\title{
Optical Nano-antennae as Compact and Efficient Couplers from Free-space to Waveguide Modes
}

\author{
Zenin, Vladimir A.; Malureanu, Radu; Volkov, Valentyn; Bozhevolnyi, Sergey I.; Lavrinenko, Andrei
}

Publication date:

2015

Document Version

Publisher's PDF, also known as Version of record

Link back to DTU Orbit

Citation $(A P A)$ :

Zenin, V. A., Malureanu, R., Volkov, V., Bozhevolnyi, S. I., \& Lavrinenko, A. (2015). Optical Nano-antennae as Compact and Efficient Couplers from Free-space to Waveguide Modes. Abstract from 1st URSI Atlantic Radio Science Conference, Gran Canaria, Spain.

\section{General rights}

Copyright and moral rights for the publications made accessible in the public portal are retained by the authors and/or other copyright owners and it is a condition of accessing publications that users recognise and abide by the legal requirements associated with these rights.

- Users may download and print one copy of any publication from the public portal for the purpose of private study or research.

- You may not further distribute the material or use it for any profit-making activity or commercial gain

- You may freely distribute the URL identifying the publication in the public portal 


\section{Optical Nano-antennae as Compact and Efficient Couplers from Free-space to Waveguide Modes}

Andrei Andryieuski ${ }^{(1)}$, Vladimir Zenin ${ }^{(2)}$, Radu Malureanu* ${ }^{(1)}$, Valentyn

Volkov $^{(2)}$, Sergey I. Bozhevolnyi ${ }^{(2)}$ and Andrei V. Lavrinenko ${ }^{(1)}$

(1) DTU Fotonik, Technical University of Denmark, Oersteds pl. 343, Kongens

Lyngby DK-2800, Denmark

(2) Department of Technology and Innovation, University of Southern Denmark, Niels Bohrs Allé 1, Odense M DK-5230, Denmark

Optical nano-antennae are one of the possible solutions for coupling free-space radiation into subwavelength waveguides. Our efforts were concentrated on coupling between an optical fibre and a plasmonic slot waveguide. Such coupling is still an issue to be solved in order to advance the use of plasmonic waveguides for optical interconnects.

During the talk, we will present our modelling optimisation, fabrication and measurement of the nano-antennae functionality. For the modelling part, we used CST Microwave studio for optimising the antenna geometry. Various antennae were modelled and fabricated. The fabrication was based on electron beam lithography and lift-off processes. The measurements were performed with scattering scanning near-field microscope and allowed the retrieval of both amplitude and phase of the propagating plasmon.

The obtained values agree very well with the theoretically predicted ones thus validating our approach. 